九州大学学術情報リポジトリ

Kyushu University Institutional Repository

\title{
Scale up of Cerrena unicolor Laccase Production
}

\section{Rola, Beata}

Department of Biochemistry, Maria Curie-Skłodowska University

\section{Karaśkiewicz}

College of Inter-Faculty Individual Studies in Mathematics and Natural Sciences, University of Warsaw I Faculty of Chemistry, University of Warsaw

Majdecka, Dominika

College of Inter-Faculty Individual Studies in Mathematics and Natural Sciences, University of Warsaw I Faculty of Chemistry, University of Warsaw

Mazur, Iwona

Department of Biochemistry, Maria Curie-Skłodowska University

他

https://doi.org/10.5109/27352

出版情報: 九州大学大学院農学研究院紀要. 58 (2)，pp.231-238，2013-09. Faculty of Agriculture， Kyushu University

バージョン :

権利関係 : 


\title{
Scale up of Cerrena unicolor Laccase Production
}

\section{Beata ROLA ${ }^{1}$, Maciej KARAŚKIEWICZ ${ }^{2,3}$, Dominika MAJDECKA', ${ }^{2,3}$ Iwona MAZUR', Renata BILEWICZ ${ }^{3}$, Jerzy ROGALSKI ${ }^{1}$ and Shoji OHGA**}

\author{
Laboratory of Forest Resources Managment, Division of Forest Environmental Science, \\ Department of Agro-environmental Sciences, Faculty of Agriculture, \\ Kyushu University, Sasaguri, Fukuoka 811-2415, Japan \\ (Received April 11, 2013 and accepted May 9, 2013)
}

\begin{abstract}
The effect of different carbon source in culture medium of wood-degrading basidiomycete Cerrena unicolor C-139 were investigated. The maximal growth and laccase synthesis in shaken flask was observed in mineral salts broth containing maltose as the carbon source and asparagine as the nitrogen source $(\mathrm{C} / \mathrm{N}=$ 17.45). The maximal laccase activities in this condition (in the end of fungus expotential growth phase) was 4-times higher (28000 nkat/l) according to control conditions with glucose. The comparison of different inoculum age preparations for laboratory scale fermentor seeding display that the best results (154 $078 \mathrm{nkat} / \mathrm{l})$ were observed when the mycelium comes from the early expotential growth phase.

In the scale-up process in SIP type 401 fermentor controlled automatically by the cascade of agitation (200-500 rpm) and gas flow of air (2-3 SLMP) giving the dissolved oxygen concentration in the range of $35-100 \%$ of initial amount, (enriched from 2 to 6 day of cultivation by the sequential addition of $10 \mu \mathrm{M}$ cupric ions) the highest laccase activity in the medium with glucose $(150,000$ nkat/l) or maltose $(145,000$ nkat/l) at 8 -th and 10-th day of cultivation were observed. The after culture fluids from these time were next concentrated and partially purified giving the crude laccase preparations Lac-G and Lac-M (from media with glucose or maltose respectively). The obtained preparations compared by ion-exchange HPLC, electrophorese and cyclic voltammetry gave no significant differences in their properties.
\end{abstract}

Key words: Cerrena unicolor, laccase, wood degrading, fermentor

\section{INTRODUCTION}

The classical (blue ones) laccases (benzenediol: oxygen oxidoreductases; EC 1.10.3.2) are multicopper enzymes containing four atoms distributed in three different copper binding sites depending on their spectroscopic characteristics (Solomon et al., 1996; Pereira et al., 2005). All these copper ions are apparently involved in oxygen reduction to water and simultaneously perform a one-electron oxidation of many aromatic substrates (polyphenols, methoxy substituted monophenols and aromatic amines in the catalytic mechanism (Rogalski and Leonowicz, 2005). In the presence of low molecular mediators with higher potential than laccase, this enzyme is capable to oxidize also non-phenolic compounds (Bourbonais et al., 1997; Banci et al., 1999)

Laccases are widespread in plants, fungi, insects and bacteria; however, only the ligninolytic organisms like white-rot fungi are the best known laccases producers and the major source of these enzymes (Claus, 2004). The enzyme possess great biotechnological potential including polymer synthesis (Huttermann et al., 2001), ethanol production (Larsson et al., 2001), bioremediation (Riva, 2006), food industry (Minussi et al., 2002)

${ }^{1}$ Department of Biochemistry, Maria Curie-Skłodowska University, Akademicka 19 Str., 20-031 Lublin, Poland

2 College of Inter-Faculty Individual Studies in Mathematics and Natural Sciences, University of Warsaw, wirki i Wigury 93 Str., 02-089 Warsaw, Poland

${ }^{3}$ Faculty of Chemistry, University of Warsaw, Pasteura 1 Str., 02-093 Warsaw, Poland

* Corresponding Author (E-mail: ohga@forest.kyushu-u.ac.jp) forest product industry (Widsten and Kandelbauer, 2008), cosmetics and nanobiotechnology (Couto and Herrera, 2006). The fact that laccase has a broad specificity for the substrates makes it attractive potential candidate as a component of biosensors (Jarosz-Wilkolazka et al., 2005; Odaci et al., 2006) for the determination of total phenols (Quan et al., 2006) and biofuel cell cathode ( Klis et al., 2007; Nazaruk et al., 2010; Bilewicz et al., 2011).

Recently, Cerrena unicolor, was determined as a new fungal source of extracellular laccase, excreting the enzyme under non-induced conditions with a rate similar to the best laccase producers. Several attempts to increase its production were undertaken, including optimization of the mediums composition and the physical parameters of the culture (Leonowicz et al., 1997; Janusz et al., 2007; Rogalski and Janusz, 2010). Reducing the costs of laccase production by optimising the fermentation process is the basic research for the industrial applications (Fenice et al., 2003).

In the present study, the scale-up process of laccase production by the white-rot fungus Cerrena unicolor was investigated.

\section{MATERIALS AND METHODS}

\section{Organism and culture conditions}

Cerrena unicolor C-139 was obtained from the culture collection of the Regensburg University and deposited in the fungal collection at the Department of Biochemistry (Maria Curie-Skłodowska University, Poland) under the strain number 139. Stock cultures of 
the fungus were stored at $4^{\circ} \mathrm{C}$ on malt agar slants. For inoculations, pieces of mycelium overgrowing agar were grown using Lindeberg \& Holm (1952) medium (pH 5.5) in stationary conical flasks for 7 days at $28^{\circ} \mathrm{C}$. The mycelial mats were subsequently collected, broken in a Waring blender (three times for $15 \mathrm{~s}$ at 10,000 rpm), and homogenates were used as inocula in aerated bioreactor cultures. For the development of a pilot scale inoculum the bioreactor-scale cultivations were performed at $28^{\circ} \mathrm{C}$ in a 3.5 l glass fermenter (BioFlo III, New Brunswick Scientific, Edison, NY, USA) containing 2.01 of the optimized Lindeberg \& Holm medium (Janusz et al., 2007). The fermenter equipped with $\mathrm{pH}-$, temperature and $\mathrm{pO}_{2}$ sensors was sterilized $\left(121^{\circ} \mathrm{C}, 40 \mathrm{~min}\right)$ and seeded with mycelial suspension (10\% of total volume). The fungal culture was run for 14 days at the aeration rate of $1 \mathrm{l}$ air min $^{-1}$ with air and stirrer speed of 150 or $300 \mathrm{rpm}$. Antifoam B emulsion (Sigma-Aldrich Fine Chemicals, St. Louis, MO, USA) was used periodically to break the foam and the $\mathrm{pH}$ was not regulated. The pilot scale fermentation was done in the SIP class 401 fermenter type 510 (New Brunswick Scientific, Edison, NY, USA) connected to the steam generating unit WA-42 (ALUX, Bielsko-Biała, Poland). The fermenter vessel contained 25L of the optimized Lindeberg \& Holm medium and was automatically sterilized at $121^{\circ} \mathrm{C}$ by $45 \mathrm{~min}$. For the inoculation the mycelial suspension from BioFlo III fermenter (2.5L) was added into the vessel via sterilized by 30 min port. The fungal culture was run for 14 days at the aeration rate of $1-3 \mathrm{l}$ air $\mathrm{min}^{-1}, 0.01 \mathrm{MPa}$ overpressure, $28^{\circ} \mathrm{C}$ and stirrer speed of 200-500 rpm. Antifoam $\mathrm{B}$ emulsion, used to break the foam, as well the samples of the medium were taken via sterilized ports. The fermenter was equipped with $\mathrm{pH}-$, temperature and $\mathrm{pO}_{2}$ sensors. In the case of pilot scale fermentation the preboiled earlier tap water was used.

\section{The effect of different carbon sources on laccase synthesis}

To study the different carbon sources on laccase production, Cerrena unicolor was grown in $50 \mathrm{ml}$ wide-mouth Erlenmeyer flasks with $15 \mathrm{ml}$ optimized earlier Lindenberg \& Holm medium (Janusz et al., 2007) containing $10 \mathrm{~g} / \mathrm{l}$ galactose, fructose, lactose, sucrose, maltose or cellobiose (all from Merck, Darmstad, Germany), instead glucose. The flasks were incubated on orbital rotary shaker Multitron (Inforce HT, Bottmingen/Basel, Switzerland) at $28^{\circ} \mathrm{C}$ and $160 \mathrm{rev} / \mathrm{min}$ for a period of 14 days.

\section{The biomass determination}

Microbial dry cell weights (DCW) were determined by filtering $30 \mathrm{ml}$ samples through predried and weighted quantitative filter papers - 41 ashless grade (Whatman, Meidstone, Kent, UK). The filter was then rinsed with distilled water $(3 \times 10 \mathrm{ml})$ prior to drying in an oven at $70^{\circ} \mathrm{C}$ for $24 \mathrm{~h}$. The results presented are the mean of DCW obtained in two separate cultivations

\section{Enzyme purification}

The after culture liquid was centrifuged at 10,000 $\times \mathrm{g}$ on CEPA LE Benchtop centrifuge (New Brunswick Scientific, Edison, NY, USA) with the flow rate $15 \mathrm{~L} / \mathrm{h}$. The supernatant was next concentrated about 25 times on the ultrafiltration system Prep/Scale TFF-6 (0.54 m²) cartridges (Millipore, Bedford, USA) with PT polyethersulfone membrane (10 kDa cut off), desalted on Sephadex G-25 column, distributed into lyophilisation vials and lyophilised in Labconco FreeZone 12 (Labconco, Kansas, MO, USA).

\section{Laccase activity and protein measurement}

Laccase activity in culture supernatant was measured spectrophotometrically at $525 \mathrm{~nm}$ in Shimadzu UV-Vis 160A spectrophotometer (Tokyo, Japan) or at BioTek ELx800 Absorbance Microplate Reader (Winooski, USA) controlled by KC-Junior (v. 1.41.8) software using syringaldazine as a substrate (Leonowicz and Grzywnowicz 1981). One nano katal (nkat) of laccase activity was defined as the amount of enzyme catalyzing the production of one nano mol of coloured product (quinone, $\varepsilon^{\mathrm{M}}=65,000 \mathrm{M}^{-1} \mathrm{~cm}^{-1}$ ) per second at $25^{\circ} \mathrm{C}$ and $\mathrm{pH} 5.5$, and expressed as nano katals per litre of culture (nkat/l). The protein concentration was determined using the Bio-Rad Protein Assay Reagent using bovine serum albumin (BSA) as standard (Bradford, 1974) or fluorometricaly on Qubit 2 with Qubit Protein Assay Kit (Ahnert et al., 2007).

\section{Carbohydrate determination}

The carbohydrate concentration was analyzed by the HPLC method on a VP chromatographic system (Shimadzu, Tokio, Japan) composed of a LC-10 AD pump, a RID-10A refractive index detector, a SCL-10A controller, a CTO 10-AS oven (all of which were controlled by Class VP 5.03 Workstation Software; Shimadzu, 1999) and sampling valve Model 7725 (Rheodyne, Berkeley, USA) with a $20 \mu \mathrm{L}$ loop. The mobile phase (Milli Q water) was run at a flow rate of $0.6 \mathrm{~mL} / \mathrm{min}$ through a Rezex RPM-monosaccharide column (7.8× $300 \mathrm{~mm} ; 1 \mu \mathrm{m}$; Phenomenex) at $75^{\circ} \mathrm{C}$. The calibration of the column was carried out using the sets of sugar and sugar alcohol standard for chromatography A and B (Merck, Darmstadt, Germany).

\section{HPLC ion exchange chromatography}

The protein profiles in after culture liquids were determined in the HPLC gradient chromatograph (Shimadzu, Tokio, Japan) composed of a Photodiode Array UV-VIS detector (SPD M10A), LC-9A pumps (all controlled by Class-M10A; v.1.64 software) and sampling valve Model 7125 (Rheodyne, Berkeley, USA) with $100 \mu \mathrm{l}$ loop. The Protein-Pak DEAE 5PW column $(7.5 \times 75$ mm; $10 \mu \mathrm{m}$; Waters-Millipore, Milford Massachusetts, USA) was stabilised by elution of buffer B (0.1 M TRIS-HCl buffer, $\mathrm{pH}$ 6.5). All analyses were run with gradient elution by using Buffer B and buffer A (0.1 M TRIS-HCl, pH 6.5 containing $0.5 \mathrm{M} \mathrm{NaCl}$ ). The gradient was partially linear, buffer A concentration increase as follows: 0\% 
(0 min), $\quad 0 \% \quad$ (10 min), $100 \% \quad$ (20 min) and $100 \%$ (25 min). The analysis time was $30 \mathrm{~min}$, the flow rate was $1 \mathrm{ml} / \mathrm{min}$ at the temperature $20^{\circ} \mathrm{C}$.

\section{Electrophoresis and gel staining}

The SDS-PAGE was run on a Mini-Protean Tetra (Bio Rad, Berkeley, CA, USA) camera in Mini-Protean TGX (4-15\%) acrylamide gels $(1 \times 83 \times 73 \mathrm{~mm})$ using molecular weight markers Precision Plus Standard (Bio Rad, Berkeley, CA, USA), according to (Laemmli, 1970). The proteins bands in the gels were visualized by staining method (Wong et al., 2000). The gels staining for laccase activities, were done as in (Kirk et al., 1968) using $100 \mathrm{ml} 0.1 \mathrm{M}$ Mc Ilvaine buffer pH 5.5 with 1\% guaiacol in $96 \%$ ethanol.

\section{Electrochemical measurements}

Electrochemical experiments were done in three electrode arrangement with $\mathrm{Ag} / \mathrm{AgCl}$ ( $\mathrm{KCl}$ sat.) reference electrode, platinum foil as the counter electrode and glassy carbon electrode (GCE, BAS) as the working electrode with surface area of $0.071 \mathrm{~cm}^{2}$. Cyclic voltammetry experiments were carried out using ECO Chemie Autolab potentiostat. All electrochemical measurements were done at $22 \pm 2^{\circ} \mathrm{C}$. All current densities were calculated using geometrical area of the electrode. The working electrodes were modified by depositing 72 micrograms of multi walled pristine carbon nanotubes (MWCNTs) (90 microliters of a suspension prepared from $12 \mathrm{ml}$ ethanol and $8 \mathrm{mg}$ nanotubes) and 48 micrograms of single walled carbon nanotubes with covalently attached naphtalene (suspension prepared in an analogous manner). Electrodes were placed in a solution of laccase, which was prepared from $20 \mathrm{mg}$ of protein in 500 microliters of Mc Ilvaine buffer solution, $\mathrm{pH}=5.3$ and incubated for 8 hours at $4^{\circ} \mathrm{C}$.

\section{Statistics}

Each experiment was run at least twice; the standard deviation of analysis was less than $10 \%$ of the mean. Other methodological details are given in tables and figures.

\section{RESULTS AND DISCUSSION}

White-rot basidiomycete Cerrena unicolor C-139 represents a new fungal source of extracellular laccase (Rogalski et al., 1999). In the previous study, we showed that the production of laccase in shaking condition was considerably enhanced by the addition of micromolar concentrations of $\mathrm{Cu}^{2+}$ into carbon and nitrogen-sufficient medium $(\mathrm{C} / \mathrm{N}=16.69)$. The fermentor laboratory scale cultivation of $C$. unicolor resulted in higher production of crude laccase than observed in submerged cultures (Janusz et al., 2007).

The white-rot fungi display a wide diversity in their response to carbon source and their concentration in nutrient media (Galhaup et al., 2002; Elisashvili et al., 2006; Wang et al., 2008).

The starting point of these studies was the selection of different carbon sources as monosaccharides (galactose, fructose) and disaccharides (cellobiose, sucrose, lactose and maltose) instead glucose in Lindeberg \& Holm medium for effective production of extracellular laccase by $C$. unicolor. Titres of laccase were measured for 14 days in shaken flask cultures. The results (Table 1) indicated that the enzyme activity reached its maximum (over 3400 nkat/l on day 12) in the medium containing maltose. But all tested disaccharides were consumed by $C$. unicolor as a carbon source that suggest the production by this fungus the enzymes degrading sucrose ( $\beta$-fructofuranosidase), lactose ( $\beta$ - galactosidase), cellobiose ( $\beta$-glucosidase) and maltose $(\alpha-$ glucosidase). The best carbon source (maltose) concentration in the medium was next optimized. The concentration of carbon (added as maltose) varied from 1 to $50 \mathrm{~g} / \mathrm{l}(2.92-146 \mathrm{mM})$ while that of nitrogen (added as L-asparagine) was $1.5 \mathrm{~g} / \mathrm{l}(11.34 \mathrm{mM}$ ) as in (Janusz et al., 2007). The $\mathrm{C} / \mathrm{N}$ molar ratio in the respective media ranged from 1.54 to 77.30 or from 3.54 to 79.41 when L-asparagine was taken into account as an additional carbon source. The results (Fig. 1) indicated that the enzyme activity reached its maximum (over 28,000 nkat/l on day 12) in cultures with a $\mathrm{C} / \mathrm{N}$ ratio of 17.45 when calculated as carbon moles in maltose and $\mathrm{L}$-asparagine to nitrogen moles in L-asparagine), i.e., containing $20 \mathrm{~g} / \mathrm{l}$ maltose $(58.40 \mathrm{mM})$ as a carbon source and $1.5 \mathrm{~g} / \mathrm{l} \mathrm{L-asparagine}(11.34 \mathrm{mM})$ as a nitrogen source.

Table 1. Laccase synthesis during C. unicolor growth on different carbon sources

\begin{tabular}{lccc}
\hline Carbon source & *HLA & Time of HLA & $\begin{array}{c}\text { Decrease } \\
\text { according to } \\
\text { glucose } \\
\text { [nkold] }\end{array}$ \\
\hline Galactose & 3000 & 8 & 1.83 \\
Fructose & 1860 & 8 & 2.95 \\
Cellobiose & 3340 & 12 & 1.65 \\
Sucrose & 2730 & 12 & 2.01 \\
Lactose & 2270 & 12 & 2.42 \\
Maltose & 3400 & 12 & 1.62 \\
\hline
\end{tabular}

*HLA-highest laccase activity

The dynamics of culture parameters was presented in (Fig. 2). The maximal laccase activities was observed in the end of $C$. unicolor expotential growth phase as well as in the time where maltose concentration drop down to $10 \%$ of initial amount and the $\mathrm{pH}$ increase to the over 7.5 level. The obtaining laccase activity was 4-times higher as that obtained in the medium with glucose (Rogalski et al., 1999).

In the submerged cultivation of Cerrena unicolor C-139 in the medium with glucose as a carbon source the highest extracellular laccase activities were observed in a carbon-sufficient and nitrogen-sufficient culture medium (Janusz et al., 2007). The synthesis of 


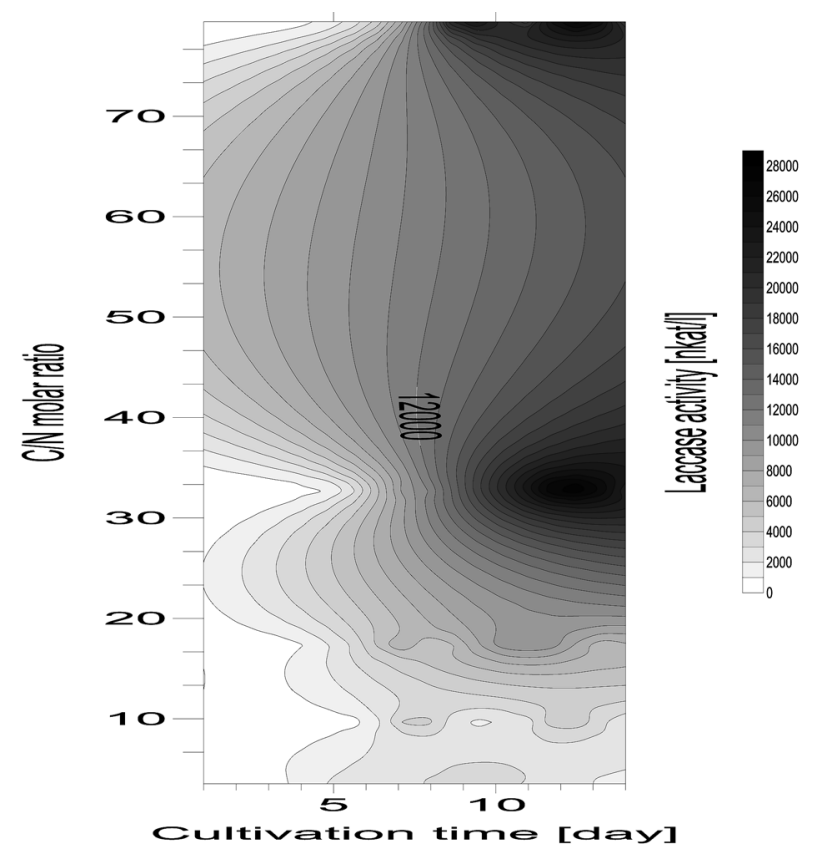

Fig. 1. The relationship between extracellular laccase synthesis and carbon/nitrogen ratio in the $C$. unicolor cultivation media.

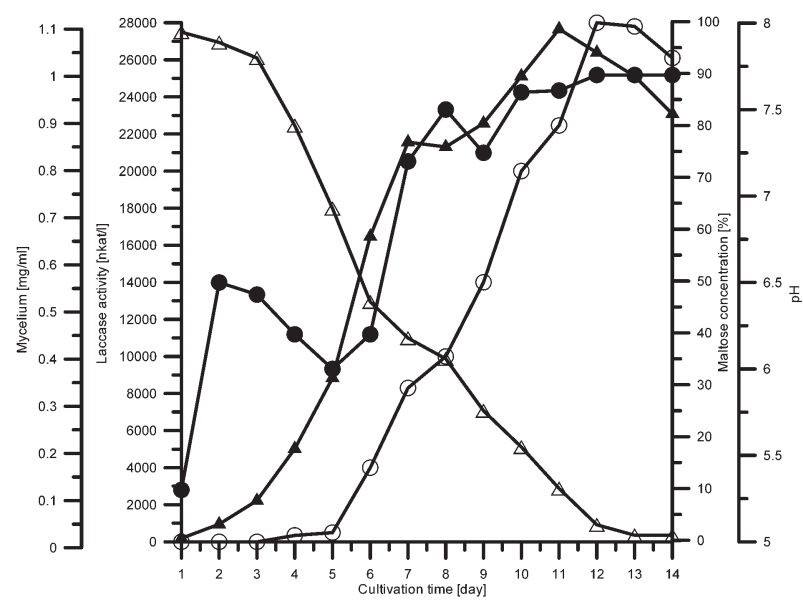

Fig. 2. Dynamics of culture parameters during C. unicolor grown in shaken flask cultures in the Lindeberg \& Holm medium containing the optimised maltose concentration (2\%). Mycelial growth- $(\mathbf{\Delta})$; laccase activity- $(\bigcirc)$; $\mathrm{pH}-($ maltose concentration $-(\Delta)$

manganese-dependent peroxidase also increase in medium where cofactor $\mathrm{C} / \mathrm{N}$ was relatively low (65.3) (Rogalski et al., 2006). In the case of Pleurotus ostreatus, Lentinula edodes and Agaricus blazei grooving in solid state cultivation the highest laccase activities were observed in the media with soybean hulls and ammonium sulphate or urea giving the ratio of $\mathrm{C} / \mathrm{N}$ on the level 5. Increase of carbon amount in the medium increase the grow of tested fungi but the laccase activities drop down in these cases (D'Agostini et al., 2011). Ganoderma genus belonging to the wood rot fungi and extensively used in Asian traditional medicine can also synthesis laccase. Production of this enzyme was extensively checked by the selection of growing media
(Simakumar et al., 2010; Ding et al., 2012 ). In the case of Ganoderma sp. the activity of laccase increase about 2 and 10 times respectively in the case when mannitol, and starch at $2 \%$ concentration were used (Simakumar et al., 2010) whereas for Ganoderma lucidum the results were opposite. In all tested carbon sources (in 2 and $8 \%$ concentrations) the laccase activities drop down according to the medium containing glucose (Ding et al., 2012).

One of the factors limiting the efficient production systems of the enzymes at bioreactor scale are the different morphological growth of filamentous fungi that have a significant effect on the rheology of the fermentation broth and the performance of the bioreactor (Couto and Toca-Herrera, 2007). The effect of broth rheology on mass, momentum and heat transfer within a bioreactor have been well studied (Charles, 1985; Funahashi et al., 1988). The most important stage in fermentor cultivation as well as in scale-up processes are inoculation. Amoung several fungal physiological properties, the age and size of the mycelial inoculum may play an important role in fungal pellets development (Glazebrok et al., 1992; Petre et al., 2005).

In the next stage of experiments the cultivation in laboratory scale fermentor for the optimization of Cerrena unicolor inoculum in 2-litre batches in a $3.5 \mathrm{l}$ fermentor were made. Biosynthesis conditions were fixed, taking into account the previous results obtained in agitated flask cultures (Janusz et al., 2007). During the first stage, we compared the effect of increasing the agitation rate of the stirrer speed from 150 to $300 \mathrm{rpm}$ on biomass amount, $\mathrm{dO}_{2}$ and laccase production by mycelia of $C$. unicolor in bioreactor cultures (Fig. 3). The laccase activity attained its maximum (about 8,000 nkat/l) after 10 days incubation at an agitation of $300 \mathrm{rpm}$ (Fig. 3B). In the same time the glucose concentration drop down to the $5 \%$ and dissolved $\mathrm{O}_{2}$ obtained level about $70 \%$ of initial amount. In the case of cultivation at $150 \mathrm{rpm}$ stirrer speed, the laccase activities increase linearly from 9 to 14 days of cultivation to the level of 6,000 nkat/l) (Fig. 3A). The consumption of the oxygen in this condition was much intensive, drooping down in the end of cultivation to the $20 \%$ of initial level. The mycelium growing curves observed in the cultivation at $150 \mathrm{rpm}$ stirrer speed was more stretched in time according to the obtained at $300 \mathrm{rpm}$. During the cultivation at $300 \mathrm{rpm}$ the mycelium in a large amount adsorbed on the glass vessel as well as on metallic elements of the fermentor. The production of erythromycin by Saccharopolyspora erythracea significantly effected by fungus clump morphology (Ghojavand et al., 2011). The morphology of the mycelium depends of its growing phase as well as from the amount of oxygen availability in the medium (Park et al., 2002; Petre et al., 2005; Gomaa and Bialy, 2009).

For these cause in the next stage of optimization the variant of the inoculum production of $C$. unicolor growing in the medium with glucose as a carbon source in $3.5 \mathrm{l}$ fermentor at $150 \mathrm{rpm}$ was used. For the inoculation of a $3.5 \mathrm{l}$ fermentor the obtained earlier mycelium 
A

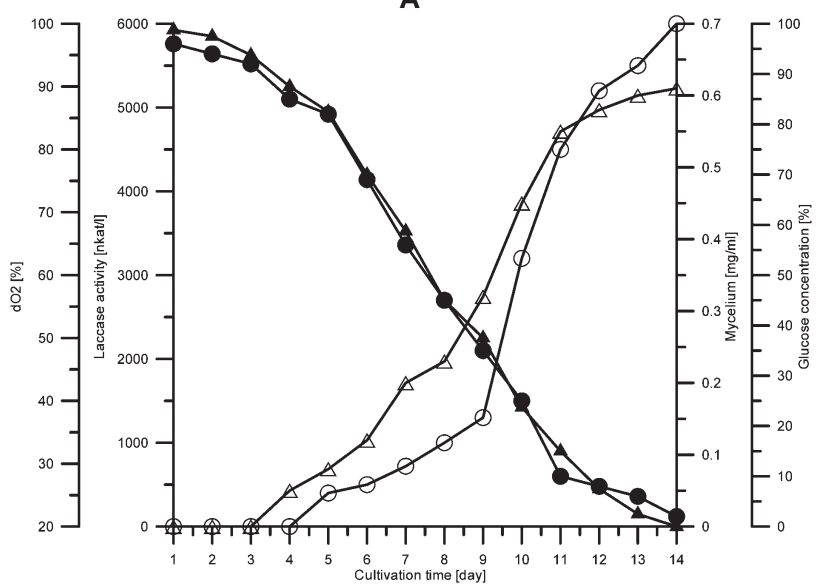

B

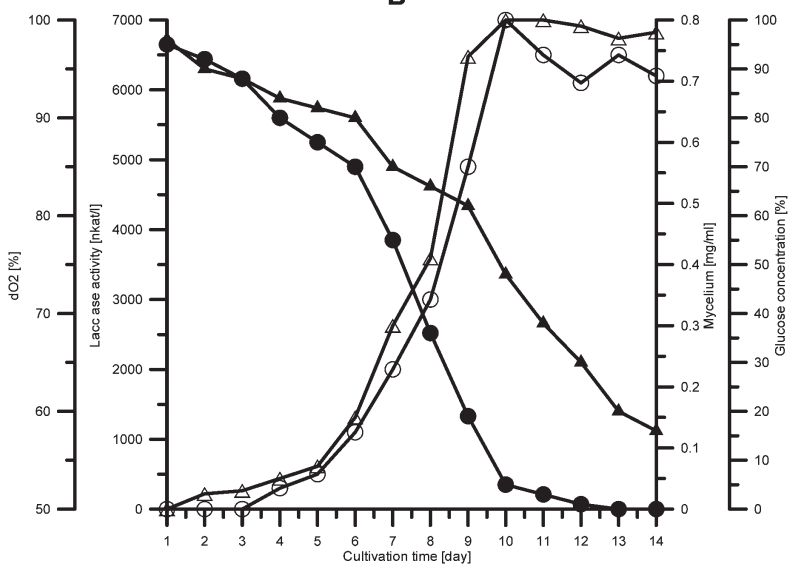

Fig. 3. Time course of laccase production, glucose consumption, $\mathrm{dO}_{2}$ concentration and mycelium growth during aerated (11/min) fermenter cultivation at $150 \mathrm{rpm}(\mathrm{A})$ and $300 \mathrm{rpm}$ (B) of C. unicolor mycelium.

Mycelial growth $-(\Delta)$; laccase activity $-(\bigcirc)$; $\mathrm{dO}_{2}$ concentration - $(\mathbf{\Delta})$; glucose concentration -

Table 2. The effect of different inoculum age on C. unicolor laccase production in laboratory scale fermentor

\begin{tabular}{cccc}
\hline $\begin{array}{r}\text { Inoculum age } \\
\text { [day] }\end{array}$ & *HLA & Time of HLA & $\begin{array}{c}\text { **Increase of } \\
\text { laccase activity } \\
\text { [fold] }\end{array}$ \\
\hline 5 & 154,078 & 12 & 25.68 \\
10 & 99,834 & 12 & 16.64 \\
12 & 69,280 & 14 & 11.55 \\
\hline
\end{tabular}

*HLA - highest laccase activity

** - increase of laccase activity according to maximal obtained during the inoculum preparation (6,000 nkat/l)

from early (5d) or late (10d) expotential growth phase, and stationary phase (12d) were used. During the cultivation the sequential addition of $10 \mu \mathrm{M}$ cupric ions were doses from 2 to 6 day of growth (Table 2). These activities were from 11 to 26 times higher than in the $\mathrm{Cu}^{2+}$ free culture (production of inoculum). The highest titres of activity was observed on 12 day of cultivation when the inoculum come from early expotential phase
(154,078 nkat/l). Using as an inoculum mycelium from late expotential phase caused about twice drop down of activity (99,834 nkat/l-12 days) and 2.5-times when mycelium comes from stationary growing phase $(69,280$ nkat/l-14 days).

Cupric ions had been reported to be strong stimulants of laccase activity also by Giardina et al. (1999) and Galhaup et al. (2002), in whose experiments up to 50 times higher levels of the enzyme were obtained in induced, compared to non-induced, cultures. The sequential suplementation after 3, 6 and 9 days of incubation resulted in markedly increased laccase titres. The optimal copper dose for the enzyme production by C. unicolor $\mathrm{C}-139$ in shaken flask cultures was found to be $10 \mu \mathrm{M}$ (Janusz et al., 2007). The optimal $\mathrm{Cu}^{2^{+}}$dose was significantly lower than that $(2.0 \mathrm{mM}$, added after 4 days of incubation) reported by Galhaup and Haltrich (2001) for submerged cultures of T. pubescens, but was still within the range of 2 to $600 \mu \mathrm{M}$ used in typical cultivation media for the production of laccase both in wild-type and recombinant strains of different basidiomycete fungi (Dittmer et al. 1997; Farnet et al. 1999; Palmieri et al. 2000; Chen et al. 2003). It had also been reported (Palmieri et al. 2000) that the induction of laccase in $P$. ostreatus occurred when the fungus was cultivated in a nutrient-rich medium supplemented with $150 \mu \mathrm{M} \mathrm{CuSO}_{4}$ at the time of inoculation.

For pilot scale laccase production the SIP type 401 fermentor with 251 batches containing 1\% glucose or $2 \%$ maltose inoculated by the mycelium from early expotential growing phase were made (Fig. 4). The dissolved oxygen level $\left(\mathrm{dO}_{2}\right)$ was automatically controlled by the cascade of agitation (200-500 rpm) and gas flow of air (2-3 SLPM - standard liters per minute) giving the dissolved oxygen concentration in the range of $35-100 \%$ of initial amount. During the cultivation the sequential addition of $10 \mu \mathrm{M}$ cupric ions were doses from 2 to 6 day of growth via sterilized port. In the case of the using the glucose as the main carbon source, the maximal laccase was observed in 8 day of cultivation (150,000 nkat/l) and for maltose in 10 day $(145,000$ nkat/l). There were a progressive rise in $\mathrm{pH}$ through the fermentation, from about 7.0 to above 8 . The maximal laccase activities are connected with reaching the stationary growing phase. In both cases the culture fluids showing the highest laccase activities were taken out from the fermentor and centrifuged for removing the mycelium. The supernatants containing laccase were next concentrated by ultrafiltaration, purified by ion-exchange chromatography on DEAE-Sepharose (fast flow) and liophylized. The obtained preparations from media containing glucose (LAC-G) and maltose (LAC-M) were compared by ion-exchange HPLC on Protein-Pak DEAE 5PW column (Fig. 5) and electrophoresis (Fig. 6). The HPLC profiles show almost identical peaks corresponding to the flow out from the column at $0.2 \mathrm{M} \mathrm{NaCl}$ (laccase proteins). In the electrophoresis comparison the both laccase preparations (LAC-G and LAC-M) showed the same activity bands in gel (Fig. 6). In the last stage of this investigation both laccase samples were used in 

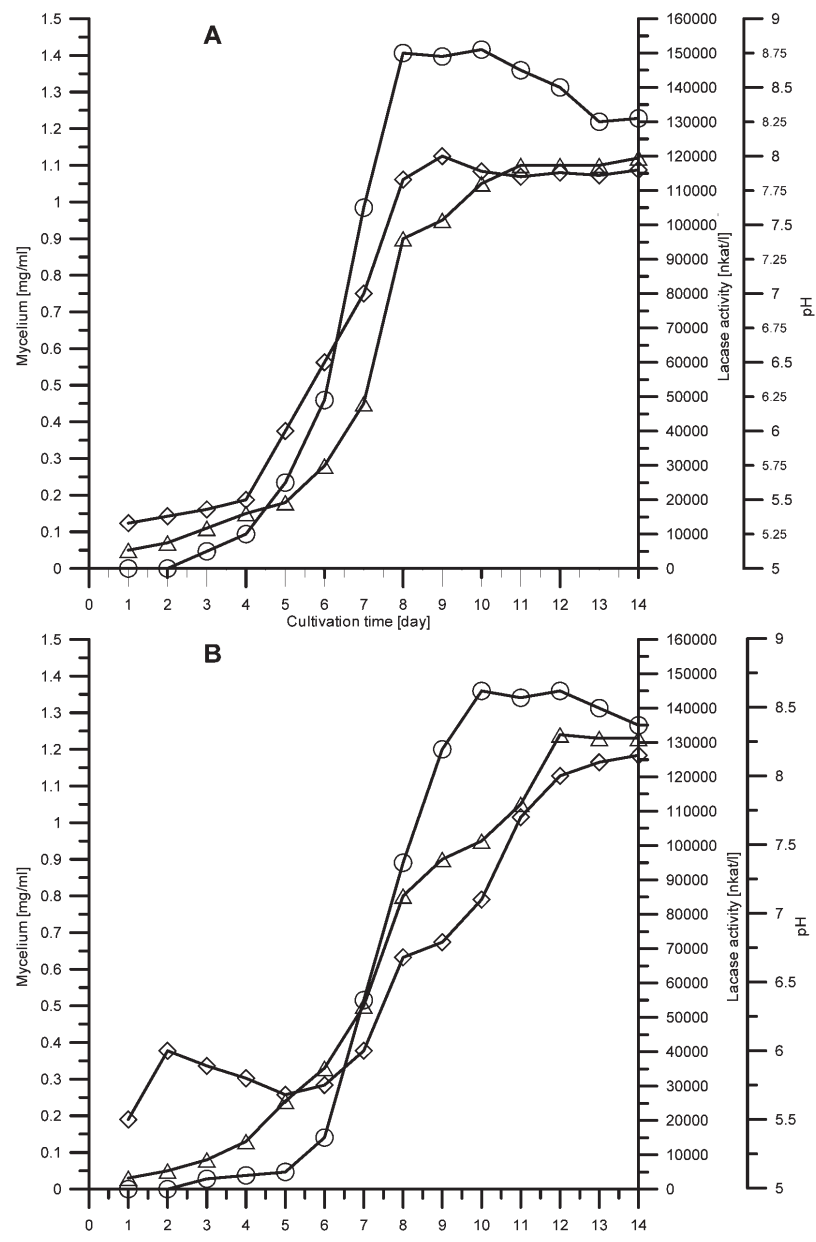

Fig. 4. The course of a typical Cerrena unicolor pilot-scale fermentation in the medium with glucose (A) and maltose (B) Mycelium growth $(\Delta) ; \mathrm{pH}(\diamond)$; laccase activity $(\bigcirc)$

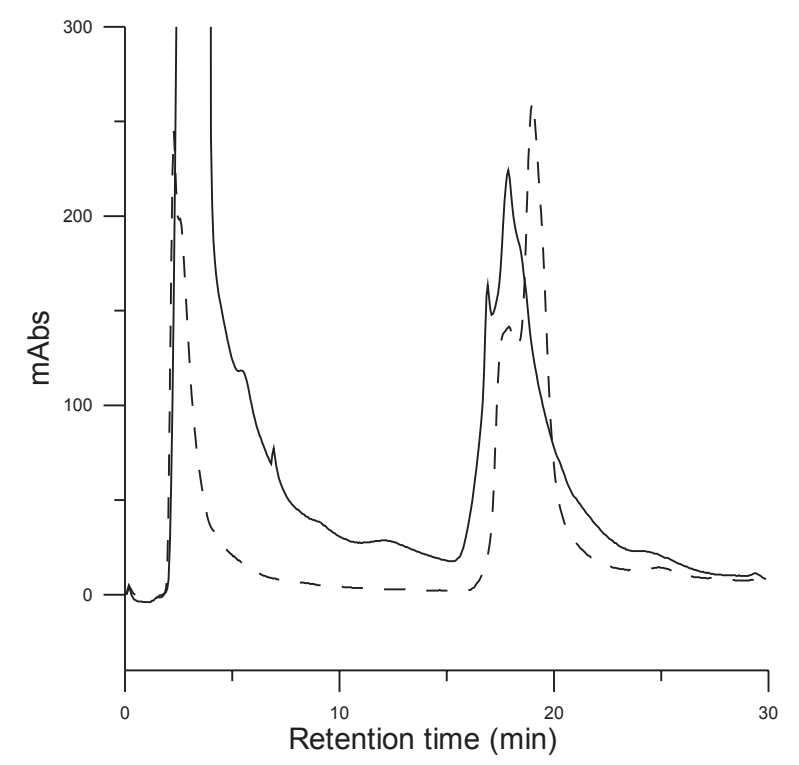

Fig. 5. The HPLC chromatogram of $C$. unicolor laccase preparates; LAC-G (solid line) and LAC-M (dashed line)

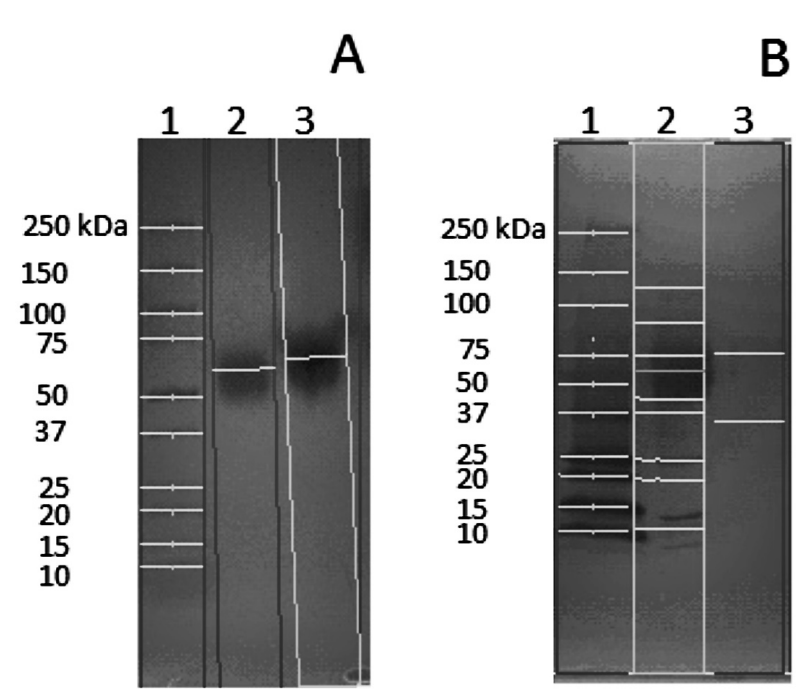

Fig. 6. The electrophoresis of purified C. unicolor laccases stained for activity (A) and SDS-PAGE stained for proteins (B) 1- molecular weight markers, 2 - LAC-G, 3 - LAC-M
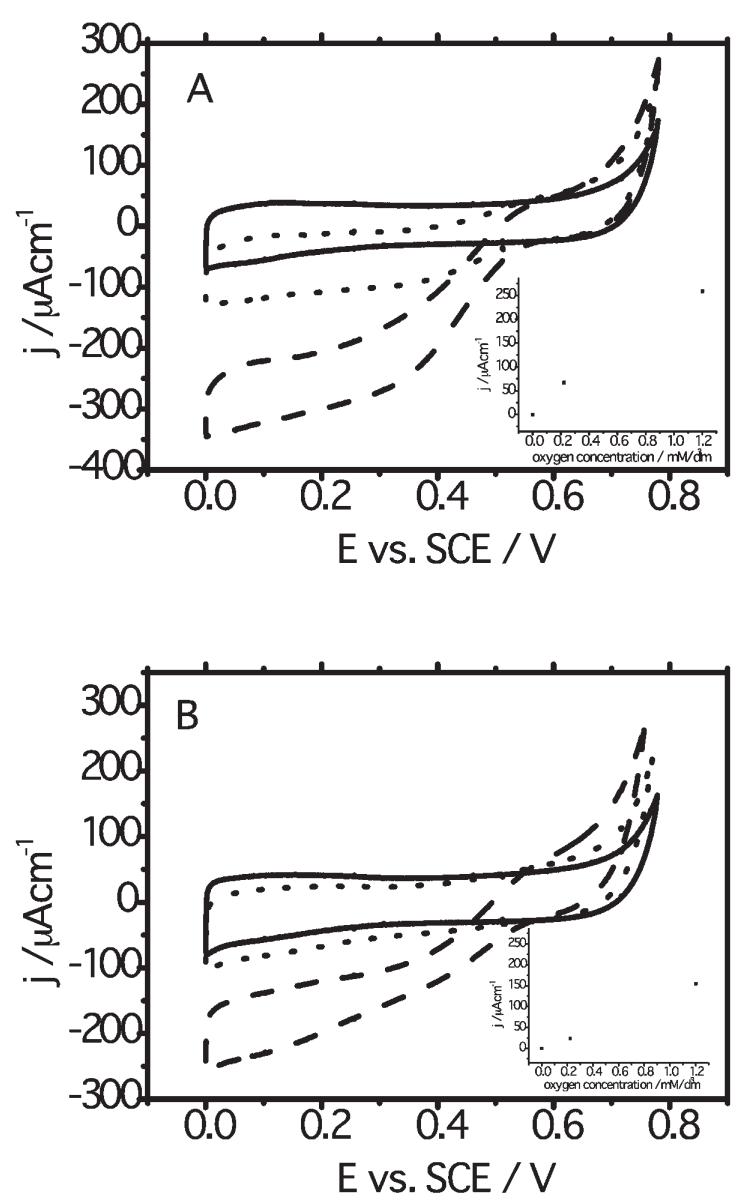

Fig. 7. Cyclic voltammograms recorded a scan rate of $1 \mathrm{mV} / \mathrm{sec}$ with C. unicolor laccase (Lac-G (A) and Lac-M (B) in $0.1 \mathrm{M}$ citrate-phosphate buffer, $\mathrm{pH}$ 5.3: 1-(solid line) argon saturated buffer, 2-(pointed line) - air saturated buffer, 3-(dashed line) - oxygen saturated buffer. Insert: Dependence of catalytic current density on the oxygen concentration 
electrochemical experiments (Fig. 7). The electrode covered with arylated carbon nanotubes and laccase was catalytically active in $4 \mathrm{e}^{-}$reduction of oxygen. Catalytic wave increases with the increasing amount of catalyst on the electrode and with increasing concentration of oxygen in the solution.

\section{Conclusions}

1. The other carbohydrates as monosaccharides (galactose, fructose) and disaccharides (lactose, cellobiose, saccharose or maltose) can be used for cultivation of C. unicolor as the sources of carbon instead glucose.

2. The optimization of maltose concentration in the medium (2\%) allow to reached the high level of laccase activity (28,000 nkat/l).

3. The process of inoculum preparation showed that the best variant was obtained when mycelium can be taken from early expotential $C$. unicolor growth phase at $150 \mathrm{rpm}$ stirrer speed.

4. The described above cultivation of $C$. unicolor in pilot scale fermentor on glucose or maltose as an only carbon sources gave the high activity laccase preparations.

5. The comparison of both laccase preparations did not show any important differences in laccase isoforms, HPLC profiles and electrochemical properties.

\section{ACKNOWLEDGEMENT}

This work was supported by the research program "Tailored Lipidic Mesophases as Novel Functional Nanomaterials in Bioenergetics and Biosensing" under the framework of Polish-Swiss Research Programme No. PSPB-079/2010, The National Center for Research and Development (NCBiR), grant NR05-0017-10/2010 (PBR11) and the research program BS/UMCS.

\section{REFERENCES}

Ahnert, N., J. Dallwig, T. Goodman, G. A. Thomas and M. Beaudet 2007 A fast, easy, accurate method for protein quantitation. J. Biomol. Tech., 18: 51

Banci, L., S. Ciofi-Baffoni and M. Tien 1999 Lignin and Mn peroxidase-catalyzed oxidation of phenolic lignin oligomers. Biochemistry 38: 3205-3210

Bilewicz, R., E. Nazaruk, K. Želechowska, J. F. Biernat, K. Stolarczyk, K. P. Roberts, G. Ginalska and J. Rogalski 2011 Carbon nanotubes chemically derivatized with redox systems as mediators for biofuel cell applications. Biocybernetics and Biomedical Engineering, 31(4): 17-30

Bourbonnais, R., M. G. Paice, B. Freiermuth, E. Bodie and S. Borneman 1997 Reactivities of various mediators and laccases with Kraft pulp and lignin model compounds. Appl. Environ. Microbiol., 12: 46274-632

Bradford, M. M. 1976 A rapid and sensitive method for the quantitation of microgram quantities of protein utilizing the principle of protein-dye binding. Analytical biochemistry 72: 248-254

Charles, M. 1985 Fermentation scale-up: problems and possibilities. Trends Biotechnol., 3: 1341-49

Chen, S., D. Ma, W. Ge and J. A. Buswell 2003 Induction of laccase activity in the edible straw mushroom, Volvariella volvacea. FEMS Microbiology Letters, 218: 143-148

Claus, H. 2004 Laccases: structure, reactions, distribution. Micron, 35: $93-96$
Couto, S. R., J. L. T. Herrera 2006 Industrial and biotechnologica applications of laccases: A review. Biotechnology Advances, 24: $500-513$

Couto, S. R. and J. L. Toca-Herrera 2007 Laccase production at reactor scale by filamentous fungi. Biotechnol. Adv., 25: 558569

D’Agostini, E. C., T. R. D’Agostini Mantovani, J. S. de Valle, L. D. Paccola-Meirelles, N. B. Colauto and G. A. Linde 2011 Low carbon/nitrogen ratio increase laccase production from basidiomycetes in solid substrate cultivation. Sci. Agric.(Piracicaba Braz. ), 68: 295-300

Dittmer, J. K., N. J. Patel, S. W. Dhawale and S. S. Dhawale 1997 Production of multiple laccase isoforms by Phanerochaete chrysosporium grown under nutrient sufficiency. FEMS Microbiology Letters, 149: 65-70

Elisashvili,V., M. Pennickx, E. Kichishvilli, M. Asatini and G. Kvestitadze 2006 Use of Pleurotus dryinus for ligninolytic enzymes production in submerged fermentation of mandarin peels and tree leaves. Enzyme Microb. Technol., 38: 9981004

Farnet, A.-M., S. Tagger and J. LePetit 1999 Effects of copper and aromatic inducers on the laccases of the white-rot fungus Marasmius quercophilus. C. R. Academy Science Paris, Sciences de la vie/Life Sciences 322: 499-503

Fenice, M., G. G. Sermanni, F. Federici and A. D'Annibale 2003 Submarged and solid-state production of laccase and Mn-peroxidase by Panus tigrinus on olive mill wastewaterbased media. J. Biotechnol., 100: 77-85

Funahashi, H., K. Hirai, T. Yoshida and H. Taguchi 1988 Mixing state of xanthum gum solution in an aerated and agitated fermenter. J. Ferment. Technol., 66: 103-109

Galhaup, C. and D. Haltrich 2001 Enhanced formation of laccase activity by the white-rot fungus Trametes pubescens in the presence of copper. Applied Microbiology and Biotechnology 56: $225-232$

Galhaup, C., H. Wagner, B. Hinterstoisser and D. Haltrich 2002 Increased production of laccase by the wood-degrading basidiomycete Trametes pubescens. Enzyme and Microbial Technology 30: 529-536

Galhaup, C., H. Wagner, B. Hinterstoisser and D. Haltrich 2002 Increase production of laccase by the wood-degrading basidiomycete Trametes pubescens. Enzyme Microb. Technol., 30: $529-536$

Ghojavand, H., B. Bonakdarpour, S. M. Heydarian and J. Hamedi 2011 The inter-relationship between inoculum concentration, morphology, rheology and erythromycin productivity in submerged cultivation of Saccharopolyspora erythraea. Brazilian J. Chem. Eng., 28: 565-574

Giardina, P., G. Palmieri, A. Scaloni, B. Fontanella, V. Faraco, G. Cennamo and G. Sannia 1999 Protein and gene structure of a blue laccase from Pleurotus ostreatus. Biochemical Journal, 34: 655-663

Glazebrook, M. A., L. C. Vining and R. L. White 1992 Growth morphoplogy of Streptomyces akiyoshiensis in submarged cultures: influence of $\mathrm{pH}$, inoculum and nutrients. Can. J. Microb., 38: 98-103

Gomaa, M. O. and A. H. Bialy 2009 Pellet morphology, broth rheology and statin production in submerged fermentation of $P$. citrinum. Global J. Biotech. Biochem., 4: 75-83

Huttermann, A., C. Mai, A. Kharazipour 2001 Modification of lignin for the production of new compounded materials. Appl. Microbiol. Biotechnol., 55: 387-394

Janusz, G., J. Rogalski and J. Szczodrak 2007 Increased production of laccase by Cerrena unicolor in submerged liquid cultures. World J. Microb. Biotechnol., 23: 1459-1464

Jarosz-Wilkołazka, A., T. Ruzgas and L. Gorton 2005 Amperometric detection of mono-and diphenols at Cerrena unicolor laccase-modified graphite electrode: correlation between sensitivity and substrate structure. Talanta, 66: 1219-1224

Kirk, T. K., J. Harkin and E. Cowling 1968 Degradation of lignin model compound syringylglicol- $\beta$-guaiacol ether by Polyporus versicolor and Stereum frustulatum. BBA, 165: 145-163 
Klis, M., E. Maicka, A. Michota, J. Bukowska, S. Sek, J. Rogalski and R. Bilewicz 2007 Electroreduction of laccase covalently bound to organothiol monolayers on gold electrodes. Electrochim. Acta, 52: 5591-5598

Laemmli, U. K. 1970 Cleavage of structural proteins during the assembly of the head of bacteriophage T4. Nature, 227: 680685

Larsson, S., P., Cassland and L. J. Jonsson 2001 Development of a Saccharomyces cerevisiae strain with enhanced resistance to phenolic fermentation inhibitors in lignocellulose hydrolysates by heterologous expression of laccase. Appl. Environ. Microbiol., 67: 1163-1170

Leonowicz, A., L. Gianfreda, J. Rogalski, M. Jaszek, J. Luterek, M. Wojtaś-Wasilewska, E. Malarczyk, A. Dawidowicz, M. FinkBoots, G. Ginalska, M. Staszczak and N-S. Cho 1997 Appearance of laccase in wood-rotting fungi and its inducibility. J. Kor. Wood Sc. Technol., 25: 29-36

Lindeberg, G. and G. Holm 1952 Occurrence of tyrosinase and laccase in fruit bodies and mycelia of some Hymenomycetes. Physiology of Plant, 5: 100-114

Minussi, R. C., G. M. Pastore and N. Duran 2002 Potential applications of laccase in the food industry. Trends Food Sci \& Technol., 13: 205-216

Nazaruk, E., K. Sadowska, J. F. Biernat, J. Rogalski, G. Ginalska and R. Bilewicz 2010 Enzymatic electrodes nanostructured with functionalized carbon nanotubes for biofuel cell applications. Anal. Bioanal. Chem., 398: 1651-1660

Odaci, D., S. Timur, N. Pazarlioğlu, U. A. Kirgöz, A. Telefoncu 2006 Effects of mediators on the laccase biosensor response in paracetamol detection. Biotechnol. Appl. Biochem., 45: 23-28

Palmieri, G., P. Giardina, C. Bianco, B. Fontanella and G. Sannia 2000 Copper induction of laccase isoenzymes in the ligninolytic fungus Pleurotus ostreatus. Applied and Environmental Microbiology, 66: 920-924

Park, J. P., Y. M. Kim, S. W. Kim, H. J. Hwang, Y. J. Cho, Y. S. Lee, Ch. H. Song and J. W. Yun 2002 Effect of aeration rate on the mycelial morphology and exo-biopolymer production in Cordyceps militaris. Proc. Biochem., 37: 1257-1262

Pereira, L., C. Bastos, T. Tzanov, A. Cavaco-Paulo and G. M. Guebitz 2005 Environmentally friendly bleaching of cotton using laccases. Environmental Chemistry Letters, 3: 66-69
Petre, M., M. X. Peng and L. X. Mao 2005 The influence of culture condition on fungal pellet formation by submerged fermentation of Cordyceps sinensis (Paecilomyces hepiali) - Cs 4 Acta Edulis Fungi (Supplement) Proceedings of the 5th International Conference on Mushroom Biology and Mushroom Products, April 9-12, Shanghai, 12: 99-104

Petre, M., M. X. Peng and L. X. Mao 2005 The influence of culture conditions on fungal pellet formation by submerged fermentation of Cordyceps sinensis (Paecilomyces hepiali) Cs 4. Acta Edulis Fungi, 12: 345-353

Quan, D., Y. Kim and W. Shin 2004 Characterization of an amperometric laccase electrode covalently immobilized on platinum surface. J. Electroanal. Chem., 561(1): 181-189

Riva, S. 2006 Laccases: blue enzymes for green chemistry. TRENDS in Biotechnology, 24(5): 219-226

Rogalski, J., A. Dawidowicz, E. Jóźwik and A. Leonowicz 1999 Immobilization of Laccase from Cerrena unicolor on Controlled Porosity Glass, J. Mol. Catal., 6: 2-39

Rogalski, J. and G. Janusz 2010 Purification of extracellular laccase from Cerrena unicolor. Prep. Bioch. Biotechnol., 40: 242-255

Rogalski, J. and A. Leonowicz 2004 Production and application of laccase. In: Encyclopedia on bioresource technology. (A Pandey ed.) Haworth Press, New York, pp. 1-736

Rogalski, J., J. Szczodrak and G. Janusz 2006 Manganese peroxidase production in submerged cultures of Nematoloma frowardii. Bioresource Technology, 97: 469-476

Solomon, E. I., U. M. Sundaram and T. E. Machonkin 1996 Multicopper oxidases and oxygenases. Chem. Rev., 96: 25632605

Wang, P., X. Hu, S. Cook, M. Begonia, K. S. Lee and H.-M. Hwang 2008 Effect of culture conditions on the production of ligninolytic enzymes by white rot fungi Phanerochaete chrysosporium (ATCC 20696) and separation of its lignin peroxidase. World J. Microbiol. Biotechnol., 24: 2205-2212

Widsten, P. and A. Kandelbauer 2008 Laccase applications in the forest products industry: A review. Enzyme and Microbial Technology, 42: 293-307

Wong, C., S. Sridhara, J. C. A. Bardwell and U. Jacob 2000 Heating greatly speeds coomasie blue staining and destaining. BioTechniques, 28: 426-432 